\title{
Evaluating Low Back Pain Patients for Prolapsed Interverbral Disc in a Kenyan Teaching Hospital
}

Authors: Ongeti K, BSc, MBChB ${ }^{1}$, Ogeng'0 J, BSc, MBChB, PhD ${ }^{1}$., Correspondence and reprints requests: Dr. Kevin Ongeti, 1-Department of Human anatomy, University of Nairobi PO Box 3019700100 Nairobi. Email: kongeti@yahoo.com

\author{
Abstract \\ Background \\ Accurate evaluation of low back pain is essential for its rational manage- \\ ment. The extent of use of clinical and imaging findings in identification \\ of prolapsed intervertebral disk varies between centers. In Kenya, the \\ diagnostic procedure is obscure. \\ Objective \\ To assess the evaluation of low back pain patients for prolapsed inter- \\ vertebral disk at Kenyatta National Hospital, a teaching and referral \\ hospital in Kenya. \\ Study Design \\ A retrospective chart study \\ Patients and Methods \\ Historical, physical and imaging findings of patients who presented with
}

low back pain and subsequently diagnosed with prolapsed inter-vertebral disk between Jan 1997 and December 2007 were evaluated.

Results

Of the six hundred and three patients (267 males, 336 females) who were evaluated, risk factors were recorded in $39.5 \%$ patients, $35.3 \%$ patients had sciatica while straight leg raising test was performed in $52.2 \%$ patients. Investigations performed in these patients included plain roentograms (38.5\%), CT scan (9.1\%) and MRI (44.1\%).

\section{Conclusion}

The evaluation of low back pain for prolapsed inter-vertebral disk was incomplete. History of sciatica, SLRT, crossed SLRT and MRI use are recommended for routine evaluation of low back pain for PID.

\section{Introduction}

Evaluation of low back pain for prolapsed intervertebral disk (PID) is based on history, physical findings and imaging examination such as Computerized Tomography (CT) scan or Magnetic Resonance Imaging (MRI). In patients with recurrent low back pain, reflex sciatica, striking tenderness on spinal processes or beside vertebrae, possible knocking pain transmitted to lower limbs and positive straight leg raising test are hallmark findings (1, 2). Ergonomic factors, age, familial predisposition, trauma, hypertension and cigarette smoking are implicated risk factors $(3,4)$ but their contribution is often undermined in patients' history. The straight leg raising test (SLRT) is not only diagnostic, but is also prognostic in evaluating patients with back pain for possible PID (2, 5). MRI is the standard radiological test for diagnosis of a herniated disk. Its use vis-à-vis CT scan, however, varies between centers (6). In spite of their value and need for consistent recording, the extent of use of clinical and MRI findings in accurate diagnosis of PID in a Kenyan setting is not documented. The study therefore aimed at evaluating the diagnostic protocol of PID among low back pain patients at Kenyatta National Hospital.

\section{Patients and Methods}

Files of patients with entry and exit diagnosis of low back pain and PID respectively seen at Kenyatta National Hospital from January 1997 to December 2007 were retrieved from the records department. Ethical approval was obtained from Kenyatta National Hospital/University of Nairobi - Ethics and Research Committee (KNH/ UON-ERC). Biodata, history of presenting complaints, risk and co-morbid factors, physical findings and imaging methods were recorded. Files with incomplete documentation were excluded.

Data collected were analyzed using SPSS ${ }^{\circledR}$ version 16.0 of Windows ${ }^{\circledR}$. Tables and histograms were used to illustrate the findings.

\section{Results}

Six hundred and three patient files with low back pain were evaluated. There were 267 (44.3\%) males and 336 $(55.7 \%)$ females. The onset of pain was sudden or insidious in $15 \%$ and $49 \%$ of patients respectively. Risk/ co-morbid factors were recorded in 238 (39.5\%) of the cases. Of these one hundred and fifty eight (66.4\%) were due to trauma, while $80(33.6 \%)$ were associated 


\section{Evaluating Low Back Pain Patients for Prolapsed Interverbral Disc in a Kenyan Teaching Hospital Ongeti K, J. Ogeng'o J.}

\begin{tabular}{lll}
\hline Straight leg raising test & N & Percentage \\
\hline Negative & 163 & 27.0 \\
\hline Positive right & 38 & 6.3 \\
\hline Positive left & 29 & 4.8 \\
\hline Bilateral positive & 35 & 14.1 \\
\hline Not done & 288 & 47.8 \\
\hline TOTAL & 603 & 100 \\
\hline
\end{tabular}

Table 1: The Straight Leg Raising Test

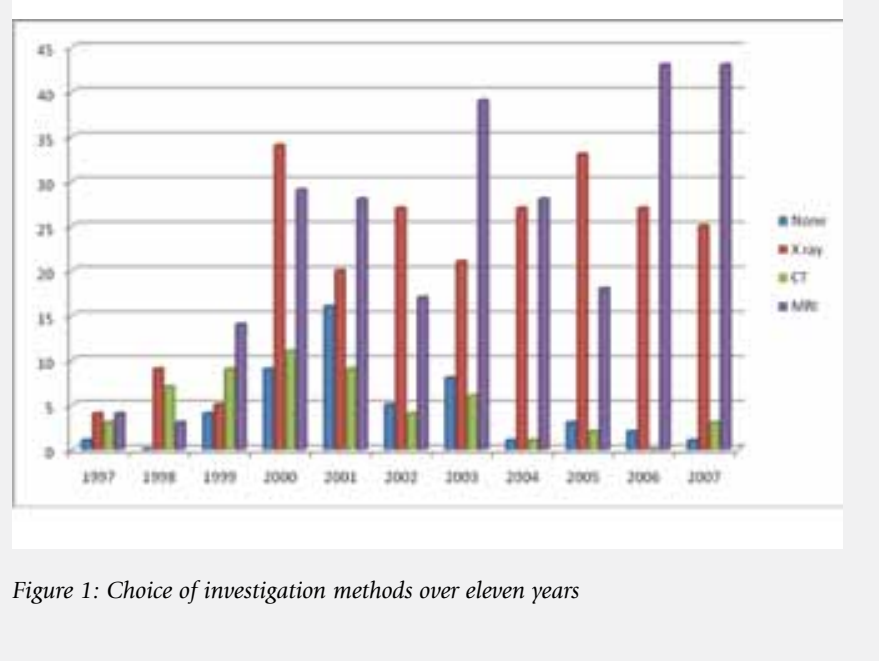

with non traumatic co-morbidities. In the majority $(60.5 \%)$ of the patients, risk/co-morbid factors were not recorded. In $47.8 \%$ of the patients, the clinicians did not document performing the straight leg raising test. Where performed, the test was negative in $61.5 \%$ of cases (table 1).

The spectrum of radiological investigations ordered in these patients included MRI (44.1\%), lumbosacral X-ray (38.5\%) and CT scan (9.1\%). In 50 patients (8.3\%) no imaging test was done. The lumbosacral $\mathrm{X}$ ray was consistently requested throughout the period while the MRI services were popular in the recent years (Figure 1).

Most (82\%) patients with sciatica had MRI features consistent with prolapsed intervertebral disk.

\section{Discussion}

Prolapsed intervertebral disk is diagnosed on history of back pain, sciatica, positive straight leg raising test and positive imaging finding consistent with prolapsed intervertebral disk (7). In the present study, $37 \%$ of patients had sciatica while $21 \%$ had a positive SLRT. Risk/comorbid factors were recorded in $39.5 \%$ of the patients. Family history, young age, male gender, ergonomic environmental factors, trauma and cigarette smoking have been associated with PID $(3,4)$. This calls for detailed history of low back pain especially family predisposition and predisposing factors.

Two hundred and twenty two (47.8\%) of the patients in the present study did not have the SLRT done. In a metaanalysis from 1965 to 1994 Vroomen et al found that pain distribution and the Lasegue test (SLRT) seemed to be the only useful clinical item in the diagnosis of PID (7). The pooled sensitivity and specificity values of the Lasegue test are $89 \%$ and 52\%, respectively $(7,8)$. Further, SLR has utility as a screen of lumbar spine stability, and can assess control of lumbar rotational movements (9) and when used with imaging, it ameliorates accuracy (10). Another significant observation of the present study is that while the crossed straight leg raising test has a relative higher specificity of $84 \%$ (7), it was not performed in any of the patients. Accordingly, it is probable that accuracy of clinical diagnosis is often undermined in patients at $\mathrm{KNH}$ and irrational treatment instituted. While MRI is the gold standard diagnostic test for prolapsed disk worldwide $(7,11)$, it is used in less than half of our patients. This could be attributed to high cost and low availability of this useful tool. Although a few patients had disc prolapse or herniation with a non-degenerated disc, there is a relationship between the presence of disc degeneration and prolapse or herniation on MRI (11). Unfortunately, MRI is so sensitive that frequently it over diagnoses PID (12).

Plain X-ray was done in $38.5 \%$ of all the patients. The consensus based on guidelines issued by the Royal College of Radiologists, however, is that plain lumbar spine $\mathrm{X}$-rays are not indicated routinely in cases of possible PID. In fact during conservative management, there is no justification for it in the absence of other indications (12). Its use in $\mathrm{KNH}$ should therefore be reduced. Observations of the current study reveal that CT scan was ordered in less than $10 \%$ of the patients. In many places, because of its wider availability, lower cost, patient acceptability and effectiveness CT scan is the investigation of choice (13). It is carried out in most places especially where MRI may not be done due to non availability, high cost, claustrophobia on the part of the patient or contraindication due to metal implants (6). Further the 
use of CT is of considerable value in determining the size, position and volume of sequestration and extent of excavation of spinal cord $(14,15)$. Accordingly, greater use of this imaging modality may reduce the cost and increase diagnostic rate at $\mathrm{KNH}$.

In conclusion, the evaluation of low back pain for prolapsed intervertebral disk at Kenyatta National Hospital is incomplete; the history of risk factors is not always taken, and the straight leg raising test, magnetic resonance imaging or computerized tomography scans are not routinely done. History of sciatica, SLRT, crossed SLRT and MRI use are recommended in evaluation of low back pain for PID.

\section{Acknowledgements}

We are grateful to Dr. Pamela Mandela for her critique, the KNH registry staff for availing the records and Mrs. Catherine Chinga for typing the manuscript.

\section{References}

1. Bi-Meng Z, Huan-Gan W, Jian S. Tuina Therapy for prolapsed lumbar intervertebral disc. J Acup Tuina Sci 2009; 2: $58-60$.

2. Iglesias-Casarrubios P, Alday-Anzola R, Ruíz-López P, et al. Lasegue's test as prognostic factor for patients undergoing lumbar disc surgery. Neurocirugia (Astur). 2004;15 (2):13843.

3. Prasad R, Hoda MF, Dhakal MM, et al. Epidemiological characteristics of lumbar disc prolapse in a tertiary care hospital. The Internet Journal of Neurosurgery. 2006. 3 (1).

4. Matsui H, Kanamori M, Ishihara H, et al. Familial predisposition for lumbar degenerative disc disease. A case-control study. Spine. 1998 1;23(9):1029-34.

5. Rebain R, Baxter GD, Mcdonough S. The passive straight leg raising test in the diagnosis and treatment of lumbar disc herniation: a survey of United kingdom osteopathic opinion and clinical practice. Spine. 2003 1;28(15):1717-24.

6. Rahalkar MD, Sawlani V. Images: Gas in the spinal canal as a sign of prolapsed intervertebral disc on plain CT. Ind J Rad Imag 2003; 13: 105 - 106.

7. Vroomen PC, De Krom MC, Knottnerus JA. Diagnostic value of history and physical examination in patients suspected of sciatica due to disc herniation: a systematic review. J Neurol. 1999; 246 (10):899-906.

8. Majlesi J, Togay H, Unalan H, Toprak S. The sensitivity and specificity of the Slump and the Straight Leg Raising tests in patients with lumbar disc herniation. J Clin Rheumatol. 2008;14 (2):87-91.

9. Jönsson B, Strömqvist B. The straight leg raising test and the severity of symptoms in lumbar disc herniation. A preoperative evaluation. Spine. 1995 1;20(1):27-30.

10. Liebenson C, Karpowicz AM, Brown SHM, et al. The active straight leg raising test and lumbar spine stability. PM\&R 2009; $1: 530$ - 536 .

11. Liu C, Cai H, Fan S, et al. Modified straight leg raising test: A hypothetical clinical adjunct to distinguish two types of lumbar disc herniation pre operatively. Med Hypoth 2009; 73: $52-55$.

12. Decandido P, Reinig JW, Dwyer AJ, et al. Magnetic resonance assessment of the distribution of lumbar spine disc degenerative changes. J Spinal Disord. 1988;1(1):9-15.

13. Lunawat SK. Taneja DK, Malviya A. Correlation between MRI and intraoperative findings in prolapse intervertebral disc. Ind J Orthop 2003; 36: 12 - 15.

14. Deane M, Moore AJ, Long AF, et al.. The effectiveness of treatment for the prolapsed lumbar intervertebral disc: A review of literature. Eur J Pub Helath 1996; 6: 15 - 20.

15. Bury T, Powell T. Prolapsed thoracic intervertebral disc. The importance of CT assisted myelography. Clin Rad 1989; 40: $416-421$. 